\title{
Microcystin Contamination and Potential of Microcystin Production in Major Drinking Water Bodies of Sri Lanka
}

\author{
Piyathilaka M.A.P.C. ${ }^{*}$, Tennekoon K.H. ${ }^{2}$, De Silva B.G.D.N.K. ${ }^{1}$ and Manage P.M. ${ }^{1}$ \\ ${ }^{1}$ Department of Zoology, Faculty of Applied sciences, University of Sri Jayewardenepura, Sri Lanka \\ ${ }^{2}$ Institute of Biochemistry, Molecular Biology and Biotechnology, University of Colombo, Sri Lanka \\ *mapcpiyathilaka@gmail.com
}

\begin{abstract}
Freshwater cyanobacterial blooms limit the utilization of drinking water due to decreased clarity, bad odor, anoxia in the water column and producing a diverse range of toxins; hepatotoxins, neurotoxins and cytotoxins. Hepatotoxic microcystin-LR (MC-LR) is the most intensively studied cyanotoxin and it is the most common type of cyanotoxin. The present study was based on qualitative and quantitative analysis of cyanotoxin in diverse water bodies in Sri Lanka and thirty one water bodies in different districts of Sri Lanka were selected for qualitative and quantitative analysis of microcystin-LR using PCR and ELISA techniques respectively along with assessment of some other selected physico-chemical water quality parameters. Presence of MCs producing genes, mcy A, mcy B and mcy E in field samples were analysed by PCR using specific primers and quantification of Microcystin-LR was done by Enzyme Link Immuno Sorbent Assay (ELISA) respectively. The results of the present study relvealed that most of the drinking water reservoirs were having acceptable physico-chemical parameters for drinking water and MC-LR contamination was ranged between $5.98 \mathrm{ppb}$ to 0.03 $\mathrm{ppb}$. The highest contamination of MC-LR was recorded in Giradurukotte Reservoir (435ppb) where moderate level of MC-LR was detected in Kurunagala lake (75.6 ppb). PCR results reveled that most of studied water bodies having MCs producing genes, mcy A, mcy B and mcy E except Labugama reservoir, Kalatuwawa reservoir, Rathkinda reservoirs, Kantale podi wewa, Minneriya wewa and Mahaweli river intake. Thus, PCR screening is a cost effective molecular biological tool to detect cyanotoxin contamination status of a water body in adavance and it may facilitate to future forcast for actual potential of cyanotoxins production and give an alarm to take nessaary treatment application for drinking water supply authorities.
\end{abstract}

Keywords: Cyanotoxin, Microcystins, PCR, ELISA, Mcy genes

Proceedings of the International Forestry and Environment Symposium 2016, Department of Forestry and Environmental Science, University of Sri Jayewardenepura, Sri Lanka. 